\title{
UNION OF GRAVITATIONAL AND ELECTROMAGNETIC FIELDS ON THE BASIS OF NONTRADITIONAL PRINCIPLES
}

\author{
Nastasenko V.A,Kherson \\ State Maritime Academy, Ukraine
}

\begin{abstract}
The traditional principle of solving the problem of combining the gravitational and electromagnetic fields is associated with the movement of the transformation of parameters from the electromagnetic to the gravitational field on the basis of Maxwell and Lorentz equations. The proposed non-traditional principle is associated with the movement of the transformation of parameters from the gravitational to the electromagnetic field, which simplifies the process. Nave principle solving this task by using special physical quantities found by M. Planck in 1900: - Planck's length, time and mass), the uniqueness of which is that they are obtained on the basis of 3 fundamental physical constants: the velocity $c$ of light in vacuum, the Planck's constant $h$ and the gravitational constant $G$, which reduces them to the fundamentals of the Universe. Strict physical regularities were obtained for the based on intercommunication of 3-th fundamental physical constants $c, h$ and $G$, that allow to single out wave characteristic $v_{G}$ from $G$ which is identified with the frequency of gravitational field. On this base other wave and substance parameters were strictly defined and their numerical values obtained. It was proved that gravitational field with the given wave parameters can be unified only with electromagnetic field having the same wave parameters that's why it is possible only on Plank's level of world creation. The solution of given problems is substantiated by well-known physical laws and conformities and not contradiction to modern knowledge about of material world and the Universe on the whole. It is actual for development of physics and other branches of science and technique.
\end{abstract}

\section{KEYWORDS}

fundamental physical constants, wave parameters gravitation and electromagnetic fields.

\section{Introduction-Connection of The Problem With Main SCIENTIFIC DIRECTIONS}

The work belongs to the sphere of quantum physics, physics of waves and physical fields, in particular - to the gravitational and electromagnetic fields, and the possibilities of their uniting, as well as to the Universe as a whole and its foundations. Many leading scientific schools and scientists of the world are engaged in the search for ways of solving these problems, since they are connected with the global problems of natural science, which have great theoretical and applied significance for the knowledge of the foundations of the material world and the Universe. They are relevant for the development of physics, other natural and technical sciences, in the conditions of a constant need to deepen knowledge about the material world and the Universe as a whole, physical fields and substances that make up them. 


\section{Problem State ANAlysis AND TASK Statement}

Until now, physical parameters of the gravitational field have been understudied, since its only really determinable characteristics is the force $F_{G}$ of the gravitational interaction of physical bodies (1), which follows from Newton's law of gravitation [1,2]:

$$
F_{G}=G \frac{m_{1} m_{2}}{r^{2}}(N)
$$

where $m_{1}, m_{2}$ - masses (kg) of two point objects situated at the $r(\mathrm{~m})$ - distant between them;

$$
\begin{aligned}
& G \text { - gravitational constant [3]: } \\
& \qquad G=6.67408(30) \cdot 10^{-11} \frac{\mathrm{m}^{3}}{\mathrm{~kg} \cdot \mathrm{s}^{2}} .
\end{aligned}
$$

All other characteristics of the gravitational field are Nat strictly defined but by analogy with the parameters of electromagnetic field in terms of empiric analogy of the law of Universal gravitation (1) and the Cullen law (3) for the electrostatic interaction of two point bodies [1, 2]:

$$
\left|F_{Q}\right|=\frac{1}{4 \pi \varepsilon_{0}} \cdot \frac{Q_{1} Q_{2}}{r^{2}}(N)
$$

where $\varepsilon_{0}$ - electric constant:

$$
\begin{gathered}
\varepsilon_{0}=8,854187817 \ldots \cdot 10^{-12} \frac{A^{2} \mathrm{~s}^{4}}{\mathrm{~kg} \cdot \mathrm{m}^{3}}, \\
Q_{1}, Q_{2} \text { - electric charges of two interacting points, } A \cdot s, \\
r-\text { distance between interacting points, } m .
\end{gathered}
$$

In this case, the empirical analogy with other laws also implies the wave structure of the gravitational field, but it does not give grounds for a rigorous determination of its wave and other real-field characteristics that actually follow from the structure of the given field, and also for the determination of the strict numerical values of these characteristics.

The solution of the problem of uniting gravitational and electromagnetic fields on the basis of superstring theory has a generalized character and also does not contain specific wave parameters.

The main way to solve the problem of uniting gravitational and electromagnetic fields was developed by A. Einstein [4] and other scientists based on traditional principles. Further, it developed within the framework of the general structural scheme of uniting forces and interactions shown in Fig. 1.

Transformation of the parameters of the electromagnetic field and the transition to a deeper level of the material world is associated with the movement of the transformation of parameters from the electromagnetic to the gravitational field on the basis of Maxwell and Lorentz equations.

The traditional way of solving this problem is connected with the transformation of the parameters of the material world in the direction of the movement from the electromagnetic field 
to the gravitational one on the basis of the Maxwell and Lorentz equations, which significantly complicates the process and does not give exact information about the final wave parameters. The general principle of deepening the levels of the material world was used.

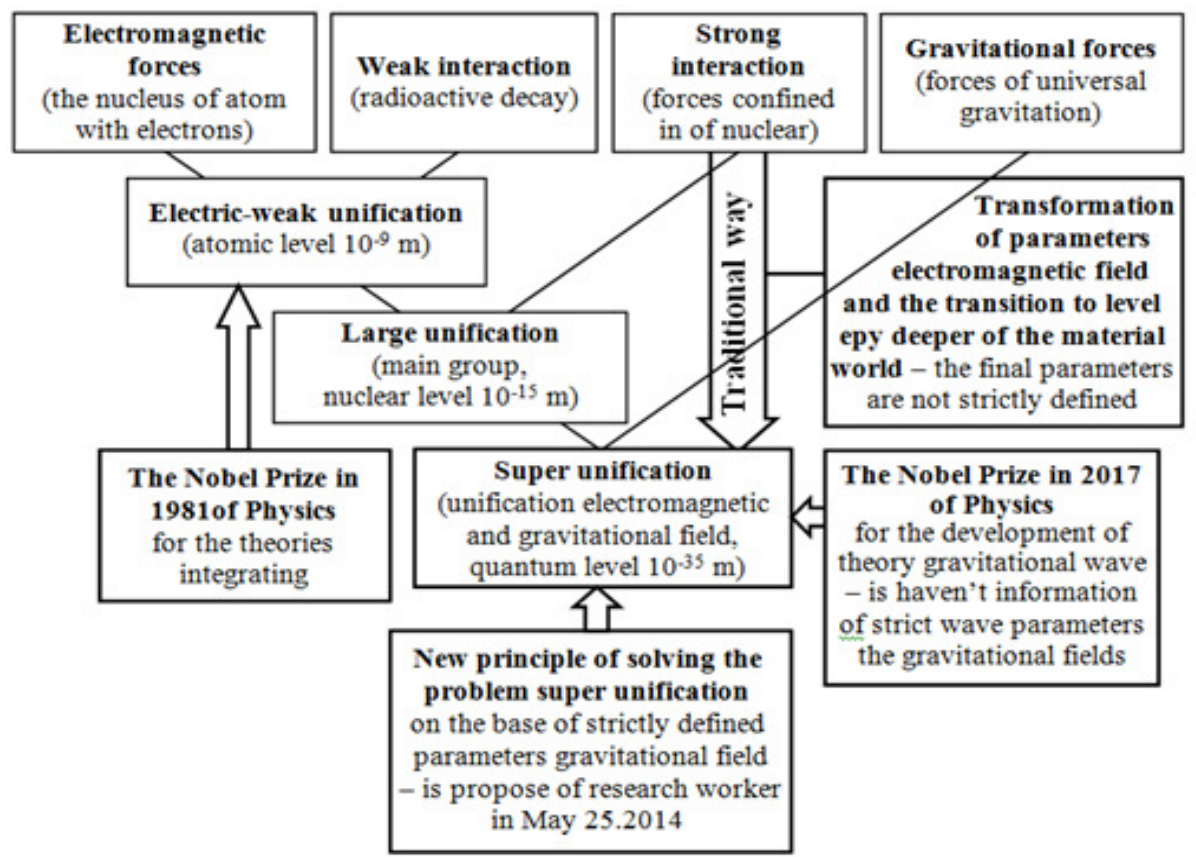

Figure 1. General structural scheme of uniting physical forces and interactions

At first, for electroweak uniting, the atomic level was used with the dimensions of material objects and wave parameters $\approx 10^{-9} \mathrm{~m}$ (Nobel Prize in Physics, 1981). For the Big unification, the level of the atomic nucleus was used with the dimensions of material objects and wave parameters $\approx 10^{-15} \mathrm{~m}$. The next level is the transition to elementary particles, among the large number and variety of which quarks are the least recognized. Therefore, uniting the electromagnetic and gravitational fields is assumed at the level of quarks. Since their parameters have not been strictly determined so far, therefore, uniting conditions were assigned to a quantum level with an approximate size and wave parameters of $\approx 10^{-35} \mathrm{~m}$. At the same time, they were not clearly reduced to special physical values discovered by M. Planck in 1900: Planck's length $l_{p}^{o}$,

time $t_{p}^{o}$, and mass $m_{p}^{o}[1,2]$, obtained on the basis of strict physical regularities consisting of 3 initial fundamental physical constants: the velocity of light in vacuum $c$, the gravitational constant $G$ and the circular Planck's constant $\hbar$, which ensures their specific parameters. This is explained by the fact that before 2000 Planck's values were considered abstract $[5,6]$.

In the developed theory of gravitational waves, marked by the Nobel Prize in Physics in 2017 [7], there are also no specific wave parameters of the gravitational field and strict conditions for its uniting with the electromagnetic field. However, they were found in as early as 2014 in [8,9], while using a non-traditional approach associated with the movement of the transformation of the parameters of the material world from the gravitational field to the electromagnetic field.

The deepening of the principles of the non-traditional approach to uniting the electromagnetic and gravitational fields is the main goal of the work performed.

The scientific novelty of the work being done is: 
Electrical \& Computer Engineering: An International Journal (ECIJ) Vol.6, No.3/4, December 2017

1) substantiation of a new strict theoretical base for defining wave and substance parameters of gravitational field;

2) finding on this basis the calculated dependencies for determining the wave and real parameters of the gravitational field and finding their numerical values;

3) a strict unification based on the found wave and real parameters of the gravitational and electromagnetic fields.

4) proof of the reliability of the scientific provisions and the results obtained.

\section{The Starting Points For ACHIEVING The GoAls Set}

Six scientific discoveries make the basis for solving the problem of union gravitational and electromagnetic fields.

In the framework of traditional knowledge about the material world [1, 2], the application of the values $l_{p}^{o}, t_{p}^{o}, m_{p}^{o}(5) \ldots$ (9) found by $\mathrm{M}$. Planck in scientific research is limited to the super dense (singular) period of the Universe birth in the Big Bang [10], which results in its materialization and the formation in it of the original physical fields and substance with parameters associated with fundamental physical constants $G, c, \hbar$.

$$
\begin{aligned}
& l_{p}^{o}=\sqrt{\frac{\hbar G}{c^{3}}}=\sqrt{\frac{1.0545718 \cdot 10^{-34}\left(\frac{\mathrm{kg} \cdot \mathrm{m}^{2}}{\mathrm{~s}}\right) \cdot 6.67408 \cdot 10^{-11}\left(\frac{\mathrm{m}^{3}}{\mathrm{~kg} \cdot \mathrm{s}^{2}}\right)}{\left[0.299792458 \cdot 10^{9}\left(\frac{\mathrm{m}}{\mathrm{s}}\right)\right]^{3}}}=1.61623 \cdot 10^{-35}(\mathrm{~m}), \\
& t_{p}^{o}=\sqrt{\frac{\hbar G}{c^{5}}}=\sqrt{\frac{1.0545718 \cdot 10^{-34}\left(\frac{\mathrm{kg} \cdot \mathrm{m}^{2}}{\mathrm{~s}}\right) \cdot 6.67408 \cdot 10^{-11}\left(\frac{\mathrm{m}^{3}}{\mathrm{~kg} \cdot \mathrm{s}^{2}}\right)}{\left[0.299792458 \cdot 10^{9}\left(\frac{\mathrm{m}}{\mathrm{s}}\right)\right]^{5}}}=5.39116 \cdot 10^{-44}(\mathrm{~s}), \\
& m_{p}^{o}=\sqrt{\frac{\hbar c}{G}}=\sqrt{\frac{1.0545718 \cdot 10^{-34}\left(\frac{\mathrm{kg} \cdot \mathrm{m}^{2}}{\mathrm{~s}}\right) \cdot 0.299792458 \cdot 10^{9}\left(\frac{\mathrm{m}}{\mathrm{s}}\right)}{6.67408 \cdot 10^{-11}\left(\frac{\mathrm{m}^{3}}{\mathrm{~kg} \cdot \mathrm{s}^{2}}\right)}}=2.17647 \cdot 10^{-8}(\mathrm{~kg}) . \\
& \hbar=\frac{h}{2 \pi}=\frac{6.626070040 \cdot 10^{-34}\left(\frac{\mathrm{kg} \cdot \mathrm{m}^{2}}{\mathrm{~s}}\right)}{2 \cdot 3.14159256}=1.054571800 \cdot 10^{-34}\left(\frac{\mathrm{kg} \cdot \mathrm{m}^{2}}{\mathrm{~s}}\right) \\
& c=0.299792458(\text { exactly }) \cdot 10^{9} \frac{\mathrm{m}}{\mathrm{s}}
\end{aligned}
$$


However, it is not clear what real objects of the material world Planck's values $l_{p}^{o}, t_{p}^{o}, m_{p}^{o}$ can be related to, therefore, they are generally considered to be abstract values. For example, comparing them with the dimensions and mass characteristics of an electron gives mutually opposite discrepancies: in size - Planck's length $l_{p}^{o}=1,61623 \cdot 10^{-35} \mathrm{~m}$, they are $10^{20}$ times smaller classical electron radius $r_{e}=2,8179409 \cdot 10^{-15} \mathrm{~m}$; Planck's mass $m_{p}^{o}=2,17647 \cdot 10^{-8} \mathrm{~kg}$ - they are $10^{23}$ times bigger electron rest mass $m_{e}=9,1093897 \cdot 10^{-31} \mathrm{~kg}$.

The first scientific discovery used in this paper is the substantiation in $[5,6]$ of the reality of the Planck's values of length $l_{p}^{o}$, time $t_{p}^{o}$ and mass $m_{p}^{o}$ due to their connection with spherical Planck's thickness layers encompassing the parameters of the observable Universe, which makes it possible to distribute the mass $m_{p}^{o}$ over the entire spherical layer.

Since within the observable Universe of the age of $T_{U}=10 \ldots 12$ billion years [10], the number of quanta of space in the first such layer can be $\approx 10^{122}[5,6]$, the Planck's mass distribution $m_{p}^{o}=2,17650 \cdot 10^{-8} \mathrm{~kg}$ in such a large number of quanta eliminates the disharmony of their masses and sizes. Planck's mass and length ratios are well coordinated with dimensional $R_{U}$ and mass $M_{U}$ characteristics of the observable Universe at any age of $T_{U}$ (9) [5...9], which follow from the law of Universal gravity [1], and are confirmed by the relation between the velocity $c$ of light in vacuum and the value of the gravitational constant $G$ in the framework of the dependence (10):

$$
\begin{gathered}
T_{U}=(10 \ldots 12) \cdot 10^{9}(\text { years }) \cdot 365.24(\text { days }) \cdot 86400(\mathrm{~s})=(3.16 \ldots 3.79) \cdot 10^{17}(\mathrm{~s}) . \\
\frac{M_{U}}{R_{U}}=\frac{m_{p}^{o} T_{U}}{l_{p}^{o} T_{U}}=\frac{c^{2}}{G}=\frac{2.17650 \cdot 10^{-8}(\mathrm{~kg})}{1.61621 \cdot 10^{-35}(\mathrm{~m})}=\frac{\left[0.299792458 \cdot 10^{9}\left(\frac{\mathrm{m}}{\mathrm{s}}\right)\right]^{2}}{6.67408 \cdot 10^{-11}\left(\frac{\mathrm{m}^{3}}{\mathrm{~kg} \cdot \mathrm{s}^{2}}\right)}=1.34664 \cdot 10^{27}\left(\frac{\mathrm{kg}}{\mathrm{m}}\right) .
\end{gathered}
$$

The relationship between $M_{U}$ and $R_{U}$ is not a strict physical and mathematical dependence, but it is confirmed by the observed age and size-mass characteristics of the Universe within the framework of the really valid law of Universal gravity $[1,5-9]$. On the basis of the obtained proof of the reality of Planck's values, the possibility of their application in scientific studies was substantiated $[5,6]$.

Since the signs of a scientific discovery are the establishment of the laws, phenomena and effects of nature previously unknown in the material world, that lead to fundamental changes in the level of scientific knowledge [11], the found connection between Planck's parameters and the spherical layer of the Universe meets these criteria and can be recognized as a scientific discovery.

The second scientific discovery used in this paper is the justification of the parameters of the minimum quantum of the Universe $l_{p}, t_{p}, m_{p}$.

In [12] it was shown that the values $l_{p}^{o}, t_{p}^{o}, m_{p}^{o}$ found by M. Planck can be attributed to the internal parameters of the minimum quantum of space in the Universe - its gravitational radius, which does not provide the possibility of their quantization with other parameters of the material world. Therefore, new Planck's parameters (11)...(13) were found in research worker [12], the 
Electrical \& Computer Engineering: An International Journal (ECIJ) Vol.6, No.3/4, December 2017

particularity of which is the determination of them on the basis of Planck's constant (14) and their real connection with the minimal quantum of space of the Universe is substantiated:

Planck's length $l_{p}$ :

$$
l_{p}=\sqrt{\frac{h G}{c^{3}}}=\sqrt{\frac{6.62607004 \cdot 10^{-34}\left(\frac{\mathrm{kg} \cdot \mathrm{m}^{2}}{\mathrm{~s}}\right) \cdot 6.67408 \cdot 10^{-11}\left(\frac{\mathrm{m}^{3}}{\mathrm{~kg} \cdot \mathrm{s}^{2}}\right)}{\left[0.299792458 \cdot 10^{9}\left(\frac{\mathrm{m}}{\mathrm{s}}\right)\right]^{3}}}=4.05128 \cdot 10^{-35}(\mathrm{~m}),
$$

Planck's time $t_{p}$ :

$$
t_{p}=\sqrt{\frac{h G}{c^{5}}}=\sqrt{\frac{6.62607004 \cdot 10^{-34}\left(\frac{\mathrm{kg} \cdot \mathrm{m}^{2}}{\mathrm{~s}}\right) \cdot 6.67408 \cdot 10^{-11}\left(\frac{\mathrm{m}^{3}}{\mathrm{~kg} \cdot \mathrm{s}^{2}}\right)}{\left[0.299792458 \cdot 10^{9}\left(\frac{\mathrm{m}}{\mathrm{s}}\right)\right]^{5}}}=13.5136 \cdot 10^{-44}(\mathrm{~s}),
$$

Planck's mass $m_{p}$ :

$$
m_{p}=\sqrt{\frac{h c}{G}}=\sqrt{\frac{6.626070040 \cdot 10^{-34}\left(\frac{\mathrm{kg} \cdot \mathrm{m}^{2}}{\mathrm{~s}}\right) \cdot 0.299792458 \cdot 10^{9}\left(\frac{\mathrm{m}}{\mathrm{s}}\right)}{6.67408 \cdot 10^{-11}\left(\frac{\mathrm{m}^{3}}{\mathrm{~kg} \cdot \mathrm{s}^{2}}\right)}}=5.45560 \cdot 10^{-8}(\mathrm{~kg}) .
$$

Planck's constant $h[3]$ :

$$
h=6.626070040(81) \cdot 10^{-34} \mathrm{~J} \cdot \mathrm{s}=6.26070040(81) \cdot 10^{-34} \frac{\mathrm{kg} \cdot \mathrm{m}^{2}}{\mathrm{~s}} .
$$

Herewith, the dependences (9), (10) remain reliable, since the parameters $M_{U}, R_{U}, T_{U}, m_{p}^{o}$ and $l_{p}^{o}$ are adequately increased by $\sqrt{2 \pi}$ value/

\section{Strictly Definition of Wave Parameters The GRAVITATIONAL FIELD}

The third scientific discovery used in this paper is the possibility of obtaining the fundamental physical constants $c, G, h$ within their dimensionality on the basis of the Planck's parameters $l_{p}$, $t_{p}, m_{p}$ [13]. For example, the gravitational constant $G$ can be expressed by the dependence (15):

$$
G\left(\frac{\mathrm{m}^{3}}{\mathrm{~kg} \cdot \mathrm{s}^{2}}\right)=\frac{l_{p}^{3}}{m_{p} t_{p}{ }^{2}}=\frac{\left[4.05128 \cdot 10^{-35}(\mathrm{~m})\right]^{3}}{5.45560 \cdot 10^{-8}(\mathrm{~kg}) \cdot\left[1.35136 \cdot 10^{-43}(\mathrm{~s})\right]^{2}}=6.67409 \cdot 10^{-11}\left(\frac{\mathrm{m}^{3}}{\mathrm{~kg} \cdot \mathrm{s}^{2}}\right) .
$$

The fourth scientific discovery used in this work is the justification of the real value of the oscillation wave of the gravitational field. 
On the basis of rigorous physicals dependences (15) and (12) a new rigorous dependence (16) was obtained in [14] for determining the gravitational constant value:

$$
G=\frac{t_{p}^{2} c_{p}^{2}}{h}=\frac{\left[13.5136 \cdot 10^{-44}(s)\right]^{2}\left[0.299792458 \cdot 10^{9}\left(\frac{\mathrm{m}}{\mathrm{s}}\right)\right]^{5}}{6.626070040 \cdot 10^{-34}\left(\frac{\mathrm{kg} \cdot \mathrm{m}^{2}}{\mathrm{~s}}\right)}=6.67405 \cdot 10^{-11}\left(\frac{\mathrm{m}^{3}}{\mathrm{~kg} \cdot \mathrm{s}^{2}}\right) .
$$

The peculiarity of the dependence (16) is the transition to 2 constants: Planck's constant $h$ (14) and the velocity of light in vacuum $c$ (8), using Planck's time $t_{p}$, which can be replaced by a strict wave characteristics - Planck's frequency $v_{p}$, as an inverse value of time $t_{p}$. This reduces the dependence (16) to the strict dependence (17), in which the frequency $v_{p}$, being the part of the gravitational constant $G$, is its wave characteristics. Thus, on a strict physical basis, its relation to the oscillation frequency of the waves of the gravitational field $v_{G}=v_{p}$ is confirmed, since constant $G$ is a component of the gravitational forces $F_{G}$ included into the law of gravitation (1):

$$
G=\frac{t_{p}{ }^{2} c^{5}}{h}=\frac{c^{5}}{v_{p}{ }^{2} h}=\frac{c^{5}}{v_{G}{ }^{2} h} .
$$

Herewith, from the physical dependence (17), the oscillation frequency of the waves of the gravitational field $v_{\mathrm{G}}$ can be obtained on a strict basis, within the framework of the dependence (18):

$$
v_{G}=v_{p}=\sqrt{\frac{c^{5}}{G h}}=\sqrt{\frac{\left[0.299792458 \cdot 10^{9}\left(\frac{\mathrm{m}}{\mathrm{s}}\right)\right]^{5}}{6.67408 \cdot 10^{-11}\left(\frac{\mathrm{m}^{3}}{\mathrm{~kg} \cdot \mathrm{s}^{2}}\right) \cdot 6.626070040 \cdot 10^{-34}\left(\frac{\mathrm{kg} \cdot \mathrm{m}^{2}}{\mathrm{~s}}\right)}}=7.39994 \cdot 10^{42}\left(\mathrm{~s}^{-1}\right) .
$$

Strictly definition of oscillation $v_{G}$ of gravitational field by dependence (18) has been obtained for the first time [8] and brings radical changes into the idea about its parameters and, finally, into the level of scientific cognition that conforms to all signs of scientific discovery [11].

The fifth scientific discovery, used in this paper, is a strict definition of the parameters of the gravitational field that follow from its oscillation $v_{G}$.

On the basis of the found value of the oscillation $v_{G}=v_{p}(20)$, it is possible to determine all other wave parameters of the gravitational field, including the following basic ones:

1. Period $T_{G}$ oscillation of wave the gravitational field:

$$
T_{G}=\frac{1}{v_{G}}=\frac{1}{7.39995 \cdot 10^{42}\left(s^{-1}\right)}=1.35136 \cdot 10^{-43}(s)=t_{p}=\sqrt{\frac{h G}{c^{5}}}=1.35136 \cdot 10^{-43}(s) .
$$

2. The wavelength of the oscillation $\lambda_{G}$, gravitational field:

$$
\lambda_{G}=\frac{c}{v_{G}}=\frac{0.299792458 \cdot 10^{9}\left(\frac{m}{s}\right)}{7.39996 \cdot 10^{42}\left(s^{-1}\right)}=4.05126 \cdot 10^{-35}(m)=l_{p}=\sqrt{\frac{h G}{c^{3}}}=4.05126 \cdot 10^{-35}(\mathrm{~m}) \text {. }
$$


Electrical \& Computer Engineering: An International Journal (ECIJ) Vol.6, No.3/4, December 2017

3. The amplitude of the oscillations $A_{G}$, of wave the gravitational field, which within the limits of the restriction of all interactions to the velocity of light $c$ at the oscillation period $T_{G}$, actually coincides with the wavelength $\lambda_{G}$ :

$$
A_{G}=\lambda_{G}=4.05126 \cdot 10^{-35}(\mathrm{~m})=l_{p}=\sqrt{\frac{h G}{c^{3}}}=4.05126 \cdot 10^{-35}(\mathrm{~m}) .
$$

4. Wave energy of the gravitational field $E_{G}$ :

$$
\begin{gathered}
E_{G}=h v_{G}=6.626070040 \cdot 10^{-34}(\mathrm{~J} \cdot s) \cdot 7.39996 \cdot 10^{42}\left(\mathrm{~s}^{-1}\right)=4.90326 \cdot 10^{9}(\mathrm{~J})= \\
E_{p}=\sqrt{\frac{h G}{c^{3}}}=4.90326 \cdot 10^{9}(\mathrm{~J}) .
\end{gathered}
$$

5. Mass equivalent $m_{G}$ of the wave energy of the gravitational field $E_{G}$, or its energy mass, which in the framework of Einstein's law $E=m c^{2}$ on the connection of total energy and mass [1], amounts to:

$$
\begin{gathered}
m_{G}=\frac{E_{G}}{c^{2}}=\frac{h v_{G}}{c^{2}}=\frac{6.626070040 \cdot 10^{-34}(\mathrm{~J} \cdot \mathrm{s}) \cdot 7.39996 \cdot 10^{42}\left(\mathrm{~s}^{-1}\right)}{\left[0.299792458 \cdot 10^{9}\left(\frac{\mathrm{m}}{\mathrm{s}}\right)\right]^{2}}=5.45561 \cdot 10^{-8}(\mathrm{~kg})= \\
=m_{p}=\sqrt{\frac{h c}{G}}=5.45561 \cdot 10^{-8}(\mathrm{~kg}) .
\end{gathered}
$$

The connection found between the mass (23) and the wave parameters of the gravitational field is an additional proof of the correctness of all the scientific propositions advanced above, since without the presence of mass, the gravitational field does not exist. In this case, the values of the energy (22) and the mass equivalent (23) refer to the entire front of the spherical wave of the gravitational field, which is confirmed by the first scientific discovery made in $[5,6]$.

Reliability of scientific statements put forward above field (18)...(22) and substance (23) parameters of gravitational field obtained on their basic is confirmed by:

1) size-mass parameters of gravitational field by the low of Heisenberg's law of in definability of imputes $(25)[1,2]$ for velocity $v_{G}$ wave gravitational field (24), which within the accuracy of the values included in it tends to the velocity of light $c(9)$ :

$$
\begin{gathered}
v_{G}=v_{p}=\frac{l_{p}}{t_{p}}=\frac{4.05128 \cdot 10^{-35}(\mathrm{~m})}{13.5136 \cdot 10^{-44}(\mathrm{~s})}=0.2997928 \cdot 10^{9}\left(\frac{\mathrm{m}}{\mathrm{s}}\right) \rightarrow c=0.299792458 \cdot 10^{9}\left(\frac{\mathrm{m}}{\mathrm{s}}\right), \\
m_{G} v_{G}=\frac{h}{\lambda_{G}}=5.45560 \cdot 10^{-8}(\mathrm{~kg}) \cdot 0.299792458 \cdot 10^{9}\left(\frac{\mathrm{m}}{\mathrm{s}}\right)=\frac{6.62607004 \cdot 10^{-34}(\mathrm{~J} \cdot \mathrm{s})}{4.05128 \cdot 10^{-35}(\mathrm{~m})}= \\
=16.35549\left(\frac{\mathrm{kg} \cdot \mathrm{m}}{\mathrm{s}}\right) .
\end{gathered}
$$

2) oscillation-mass parameters of gravitational field by de Broil $[1,2]$ wave (26) if Plank's energy of gravitational field radiation (21) connected with full Plank's energy $E_{G}=h v_{p}$ and by Einstein's 
Electrical \& Computer Engineering: An International Journal (ECIJ) Vol.6, No.3/4, December 2017

law $E_{G}=m_{G} c^{2}[1,2]$ of mass its component substance obtained of the connection of mass and energy:

$$
v_{G}=\frac{E_{G}}{h}=\frac{m_{G} c^{2}}{h}=7.39995 \cdot 10^{42}\left(s^{-1}\right)=\frac{5.45560 \cdot 10^{-8}(\mathrm{~kg}) \cdot\left[0.299792458 \cdot 10^{9}\left(\frac{\mathrm{m}}{\mathrm{s}}\right)\right]^{2}}{6.626070040 \cdot 10^{-34}(\mathrm{~J} \cdot \mathrm{s})}(\mathrm{Hz}) .
$$

Values (24)...(26) obtained on the basis of repeatedly approved reliably physical laws allow to maintain that field structure with Planck's mass (23) and wave parameters (18)...(22) of minimum possible in the Universe $[5,13]$ length of the wave $\lambda_{G}$ and maximum possible wave oscillation $v_{G}$ is gravitational field, quant of space composing it having sizes (11) being domains of the environment of gravitational field which because of their very small size-mass parameters can be named graviton, by analogy with neutrino, its help talking this parameters.

\section{UNIFICATION OF GRAVITATIONAL FIELD WITH ELECTRO- MAGNETIC FIELD}

The complexity of unifying gravitational and electromagnetic fields being so difficult problem to solve can explained by the fact that till now their wave parameters were not Known, that's why it was not clear what and how can unified. The wave parameters of the gravitational field (18) ... (22) found in this paper create such an opportunity, which provides in this paper the principle of solving the problem of uniting fields on the basis of the transformed this parameters movement from the gravitational field to electromagnetic one.

The 6th scientific discovery used in this work is the justification of uniting the gravitational and electromagnetic fields according to their parameters.

Analysis of the dependence (18) showed that it simultaneously includes 3 types of fundamental physical constants related to 1 ) the total energy of substance $(c), 2)$ the thermal radiation $(h), 3)$ the gravitational interaction $(G)$, which allows us to refer the frequency $v_{G}$ to other physical fields, including the frequency of the United Field of the Universe.

Taking into account the obtained wave characteristics (18)....(22) it can be strictly maintained that gravitational field can only by unified with electromagnetic field having the same wave characteristics. Thus, It can be summed up that unification of given fields is possible only on Plank's level material world. This conclusion is confirmed:

indirectly by numerical equality of the values of wave (22), of Plank's dynamic (27) and potential (28) energies of substance gravitation field within the framed of the laws known [1,2] for their definition:

$$
\begin{gathered}
E_{p}=m_{p} c^{2}=5.45560 \cdot 10^{-8}(\mathrm{~kg}) \cdot\left[0.299792458 \cdot 10^{9}\left(\frac{\mathrm{m}}{\mathrm{s}}\right)\right]^{2}=4.90326 \cdot 10^{9}(\mathrm{~J}), \\
E_{p}=m_{p} g_{p} l_{p}=5.45560 \cdot 10^{-8}(\mathrm{~kg}) \cdot 2.21846419 \cdot 10^{51}\left(\frac{\mathrm{m}}{\mathrm{s}^{2}}\right) \cdot 4.05128 \cdot 10^{-35}(\mathrm{~m})=4.90326 \cdot 10^{9}(\mathrm{~J}),
\end{gathered}
$$

where $g_{p}$ - Plank's acceleration of free fall (29):

$$
g_{p}=\frac{l_{p}}{t_{p}^{2}}=\frac{4.05128 \cdot 10^{-35}(m)}{\left[13.5136 \cdot 10^{-44}(s)\right]^{2}}=2,21845 \cdot 10^{51}\left(\frac{m}{s^{2}}\right)
$$


strictly by common for all these energies functional dependency (30) obtained by substituting in dependences (22), (27), (28) for dependences (18), (13), (11), (12) for Plank's parameters $v_{p}=v_{G}$, $m_{p}=m_{G}, l_{p}=\lambda_{G}, t_{p}=T_{G}$ which make them up.

$$
\begin{gathered}
: \quad E_{G}=E_{p}=h v_{p}=m_{p} c^{2}=m_{p} g_{p} l_{p}=h \sqrt{\frac{c^{5}}{h G}}=\sqrt{\frac{h c}{G}} \cdot c^{2}=\sqrt{\frac{h c}{G}} \cdot \frac{\sqrt{\frac{h G}{c^{3}}}}{\left(\sqrt{\frac{h G}{c^{5}}}\right)^{2}} \cdot \sqrt{\frac{h G}{c^{3}}}= \\
=\sqrt{\frac{h c^{5}}{G}}=\sqrt{\frac{6.626070040 \cdot 10^{-34}(\mathrm{~J} \cdot \mathrm{s}) \cdot\left[0.299792458 \cdot 10^{9}\left(\frac{\mathrm{m}}{\mathrm{s}}\right)\right]^{5}}{6.67408 \cdot 10^{-11}\left(\frac{\mathrm{m}^{3}}{\mathrm{~kg} \cdot \mathrm{s}^{2}}\right)}}=4.90326 \cdot 10^{9}(\mathrm{~J}) .
\end{gathered}
$$

strictly - by a general theoretical test of the results based on the dependencies:

$$
m_{p} v_{p}=\frac{h}{\lambda_{p}}, \text { или } \frac{E_{p}}{c}=\frac{h}{\lambda_{p}}, \text { или } \frac{h v_{p}}{c}=\frac{h}{\lambda_{p}},
$$

Finally transforming the third dependence in the expression (31), we obtain the relationship of the new wave parameters with the velocity of light $c$, as confirmation of its reliability:

$$
v_{G} \lambda_{G}=v_{p} \lambda_{p}=7,39995 \cdot 10^{42}\left(c^{-1}\right) \cdot 4,05126 \cdot 10^{-35}(M)=0,2997912 \cdot 10^{9}\left(\frac{M}{c}\right) \rightarrow c=0,299792458 \cdot 10^{9}\left(\frac{M}{c}\right) .
$$

In this case, the found wave parameters of the gravitational field (14) - (18) can also be regarded as the wave parameters of a constant electric current and a constant magnetic field, since their "constancy" is apparent and is due only to the sensitivity of measurements of modern measuring instruments.

Within the frames of the analogies of gravitational and electromagnetic fields basing on the obtained wave parameters (18)...(22) it can be possible to define all other wave characteristics of gravitational field and to evaluate the possibility of interactions with other objects and fields of material world that allows to deepen and widen the knowledge of the Universe.

Experimental proof of gravitational and electromagnetic fields unification is the hovering of ring superconductor (figure 2) where direct current. Is induced resulting in the appearance of the a genetic field with oscillation and amplitude of oscillation the same in size but opposite in phase of oscillation and amplitude of gravitational field oscillation (other wave there wouldn't be the effect of hovering).
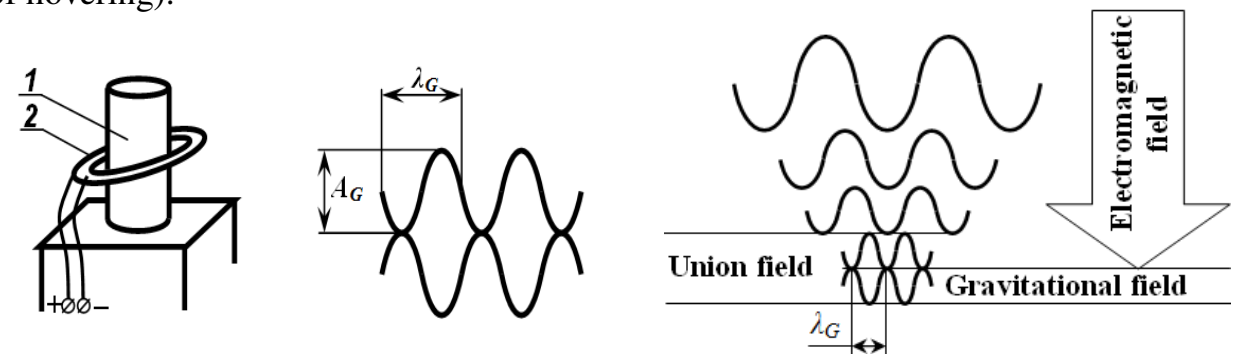

Figure 2 - Diagram of the sticking of a ring superconductor 2, cooled by means of the container 1 with liquid helium, when a constant electric current is excited in it, and the wave structure of the physical fields formed herewith. 
Electrical \& Computer Engineering: An International Journal (ECIJ) Vol.6, No.3/4, December 2017

Since dependence (18) implies that for the gravitational field $v_{G}=$ const, then for all other wave parameters, except for Planck's $\lambda_{G}$, uniting the gravitational and electromagnetic fields is impossible (Fig. 2).

Thus, the possibility of uniting the electromagnetic and gravitational fields on the basis of the principle of transformations from the parameters gravitational field is strictly confirmed.

The main results of this scientific work were presented and recommended for publication on 2-th International Conference on Quantum Physics and Quantum Technology, Berlin, Germany, [15] and 3-th International Conference on Theoretical and Condensed Matter Physics in New York, USA [16],

\section{CONCLUSION}

A fundamentally new method for determining the wave and real parameters of the gravitational and the Unified fields is proposed on the basis of the fundamental physical constants $G, c, h$. New physical dependencies, laws and regularities strictly follow from earlier known physical laws and regularities and do not contradict them.Strictly obtained frequencies $v_{G}$ gravitational field from dependency (18) was obtained for the first time, and wave parameters connected with it were obtained for the first time in the paper [5,8], which bring radical changes into the notion about its parameters and in the end into the general level of scientific cognition that's why it meets all the requirements of scientific discovery [11].A rigorous determination of the frequency $v_{G}$ of the gravitational field by the dependence (18) showed that it is a fundamental physical constant that is even more significant for the Universe than the fundamental physical constants $G, c, h$, since in different measurement systems they take different values, and their aggregate compensates for mutual changes in their dimensionality, making the final value of $v_{G}$ a constant value for the entire Universe. Strictly substantiation of gravitational and electromagnetic fields unification was obtained for the first time in the paper [8] and more precise definition was given by the dependencies (26)...(30) which bring radical changes into the general level of scientific cognition that it also meets all requirements of scientific discovery [11]. Strictly constancy of the oscillation of the waves of gravitational field $v_{G}=$ const (18), excludes the possibility of the unification of gravitational and electromagnetic fields on other levels except Plank's ones with wave length $\lambda_{p}=$ $\lambda_{G}$ and oscillation $v_{p}=v_{G}$, which is confirmed by the found regularity (30)

\section{REFERENCES}

[1] Alekseev D. V., Bonch-Bruevich A. M., Voronov-Romanov A. S. et al. (1983). Phizicheskij encyclopedicheskij slovar. Pod red. A. M.Prohorov (Ed.). Moskva : Sov. Encyclopedia.- 928 S.

[2] Belov A.F., Voskobounikov V.G. et. Al. (1989) Politechnicheskij slovar /Red. col.: A.Yu. Ishlinskij (gl. red.) i dr, -3-e izd., pererab. i dop. -M.: Sov. Encyclopedia,. -S. 134, 382, 486, 638-640.

[3] CODATA Internationally recommended values of the Fundamental Physical Constants (Интернет pecypc).

[4] Parker B. Mechta Ejnstejna. V poiskah edinoj teorii stroenija Vselennoj. - SPb.: Amfora, 2000. - 333 S.

[5] Nastasenko V.A. (2000) Etalon massu v elementah kvantovoj phiziki: Mashinostroense i technosphera na rubeje XXI v. Sb. trudov VII Megdunar. nauch.-techn. konf. v Sevastopole. Doneck: DonGTU, T1. -S. 95-100.

[6] Nastasenko V.A. (2006) Ayaliz granuchno mojluvyh csharuvatuh ctryktur: Fizika i himija tverdogo tila. -Ivano-Frankivsk. Prikarp. nac. university. T.7. №4. -S.793-797. 
Electrical \& Computer Engineering: An International Journal (ECIJ) Vol.6, No.3/4, December 2017

[7] https://www.nobelprize.org/nobel_prizes/physics/laureates/2017/press.html

[8] Nastasenko V. A. (2014). Strogoe opredelenie volnovihkh parametrov gravitacionnogo polya $\mathrm{i}$ objhedinenie gravitacionnogo i ehlektromagnitnogo poleyj: Suchasni informaciyjni ta innovaciyjni tekhnologiï na transporti. Mizhnarodna naukovo-praktichna konferencia. Kherson, KhDMA, 198-204.

[9] Nastasenko V. A. (2014). Novue osnovu dlja strogogo opredelenia volnovihkh parametrov gravitacionnogo polya i objhedinenie gravitacionnogo i ehlektromagnitnogo poleyj: Naukoviyj visnik KhDMA: naukoviyj zhurnal. Kherson, 1 (10), 213-222.

[10] Silk Dj. (1982). Boljshoyj vzrihv. I. D. Novikova (Ed.). Moskva : Mir. - 391.

[11] Civiljniyj kodeks Ukrainu (2003). Zakonu Ukrainu. Kyiv : Shkola, -142.

[12] Nastasenko V. A. (2012). Obgruntuvannya parametriv minimaljnogo kvanta prostoru Vsesvitu: Naukoviyj visnik KhDMA: naukoviyj zhurnal. Kherson, 1 (6), 285-297.

[13] Nastasenko V. A. (2004). Otkrutie predelno vozmojnuh volnovuh parametrov: Theoria and tehnica peredachi, priema i pererabotki informacii. 10-ja jubilejnaja Megdunarodnaja conferencia. Kharkov : KhNURE. Vol. 1, 30-31.

[14] Nastasenko V. A. (2013) O vozmozhnosti utochneniya znacheniya gravitacionnoyj postoyannoyj raschetnihm putem: Vihsokoproizvoditeljnihe vihchisliteljnihe sistemih 2013. Kiev, NTUU «KPI», 266-272 www HPS-UA-13

[15] Valentyn A. Nastasenko New principles of solving the problem of combining the gravitational and electromagnetic fields /2-th International Conference on Quantum Physics and Quantum Technology. September 25-26 2017 in Berlin, Germany. - P. 43.

[16] Valentyn A. Nastasenko On the Possibility of Refining the Gravitational Constant and Solving the Task of Integrating the Gravitational and Electromagnetic Fields /3-th International Conference on Theoretical and Condensed Matter Physics. October 19-21 2017 in New York, USA. - P. 61.

\section{AUTHORS}

Valentyn Alexeevich Nastasenko - Professor of department of transport technologies of Kherson State Maritime Academy, Kherson, Ukraine. Candidate of Technical Sciences (Ph. D. )The scope of scientific interests includes quantum physics, gravitation theory, and the foundations of the material world and the birth of the Universe - the author of more than 50 scientific papers in these fields.

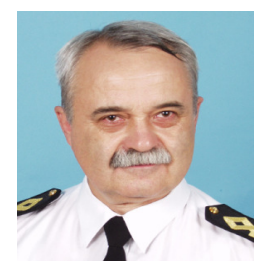

